\title{
Catching up at the regional level
}

\author{
Citation for published version (APA):
}

Oude Wansink, M. J., \& Maks, J. A. H. (1997). Catching up at the regional level. METEOR, Maastricht University School of Business and Economics. METEOR Research Memorandum No. 042 https://doi.org/10.26481/umamet.1997042

Document status and date:

Published: 01/01/1997

DOI:

10.26481/umamet.1997042

Document Version:

Publisher's PDF, also known as Version of record

\section{Please check the document version of this publication:}

- A submitted manuscript is the version of the article upon submission and before peer-review. There can be important differences between the submitted version and the official published version of record.

People interested in the research are advised to contact the author for the final version of the publication, or visit the DOI to the publisher's website.

- The final author version and the galley proof are versions of the publication after peer review.

- The final published version features the final layout of the paper including the volume, issue and page numbers.

Link to publication

\footnotetext{
General rights rights.

- You may freely distribute the URL identifying the publication in the public portal. please follow below link for the End User Agreement:

www.umlib.nl/taverne-license

Take down policy

If you believe that this document breaches copyright please contact us at:

repository@maastrichtuniversity.nl

providing details and we will investigate your claim.
}

Copyright and moral rights for the publications made accessible in the public portal are retained by the authors and/or other copyright owners and it is a condition of accessing publications that users recognise and abide by the legal requirements associated with these

- Users may download and print one copy of any publication from the public portal for the purpose of private study or research.

- You may not further distribute the material or use it for any profit-making activity or commercial gain

If the publication is distributed under the terms of Article $25 \mathrm{fa}$ of the Dutch Copyright Act, indicated by the "Taverne" license above, 


\title{
Catching Up At The Regional Level
}

\author{
M.J. Oude Wansink \\ Maastricht Economic Research Institute on Innovation and Technology \\ University of Maastricht, The Netherlands \\ e-mail: m.oudewansink@algec.unimaas.nl
}

\author{
J.A.H. Maks \\ Department of Economics \\ University of Maastricht, The Netherlands \\ e-mail: h.maks@algec.unimaas.nl \\ paper prepared for the congress of the \\ European Regional Science Association \\ Rome, Italy, August 1997
}

\begin{abstract}
A convenient way to find out how things are going is by taking a look at your neighbours. In this paper we develop a method for the evaluation of regional economic performance based on an input-output (IO) framework. Once we defined economic criteria for measuring this performance, such as real GDP per worker or employment per output unit, we pick out the 'best' performing region per sector. Taken together, they describe an optimal regional industrial structure for all sectors, a so called 'optimal' input coefficients table. On the basis of this table, we will investigate the causes of regional convergence. Furthermore, this table will be used as a point of reference for economic policy makers at the regional level. Structural deviations from the 'optimal' industrial structure may be reasons for policy action, so that the industrial structure can be evaluated in a normative way. In this paper, we investigate those deviations for 11 regions and 29 sectors in the Netherlands for the 1980-1992 period. The central focus is on the question how regional policy makers can improve regional economic performance by adjusting the regional industrial structure.
\end{abstract}




\section{Introduction}

A convenient way to find out how things are going is by taking a look at your neighbours. In this paper we develop a method for the evaluation of regional economic performance based on an input-output (IO) framework. Once we defined economic criteria for measuring this performance, such as real GDP per worker or employment per output unit, we pick out the 'best' performing region per sector. Taken together, they describe an optimal regional industrial structure for all sectors, a so called 'optimal' input coefficients table. On the basis of this table, we will investigate the causes of regional convergence. Furthermore, this table wil be used as a point of reference for economic policy at the regional level. Structural deviations from the 'optimal' industrial structure may be reasons for policy action, so that the industrial structure can be evaluated in a normative way. In this paper, we investigate those deviations for 11 regions and 29 sectors in the Netherlands for the 1980-1992 period. The central focus is on the question how regional policy makers can improve regional economic performance by adjusting the regional industrial structure.

The organization of the paper is as follows. In section 2, we present the regional structure of the Netherlands and discuss the data. In section 3, we concentrate on regional convergence in the Netherlands in the 1980-1992 period. In section 4, we discuss our (input-output) approach to regional convergence. We test our approach by using (the growth of) real GDP per worker in section 5 and employment per output unit in section 6 . Section 7 summarizes and concludes.

\section{Regional Structure and Data}

In Figure 1 (next page), we depicted the map of the Netherlands, divided in 12 regions. ${ }^{1}$ Each region is autonomous in defining its own economic policy. We consider this choice of regional aggregation, based on the ability of regions to define their own economic policy, suitable for the evaluation of possible causes of regional convergence. For each region, we have data available for 29 business sectors: 1 agricultural sector, 13 industrial sectors and 15 services sectors (see Annex 1 for more details). Our economic indicators, which are real GDP per worker and employment per output unit, are available from publications by the Dutch Central Bureau of Statistics (CBS, Regionaal Economische Jaarcijfers and National Accounts) and the Dutch Central Planning Bureau (CPB, Lange Termijn Reeksen). 


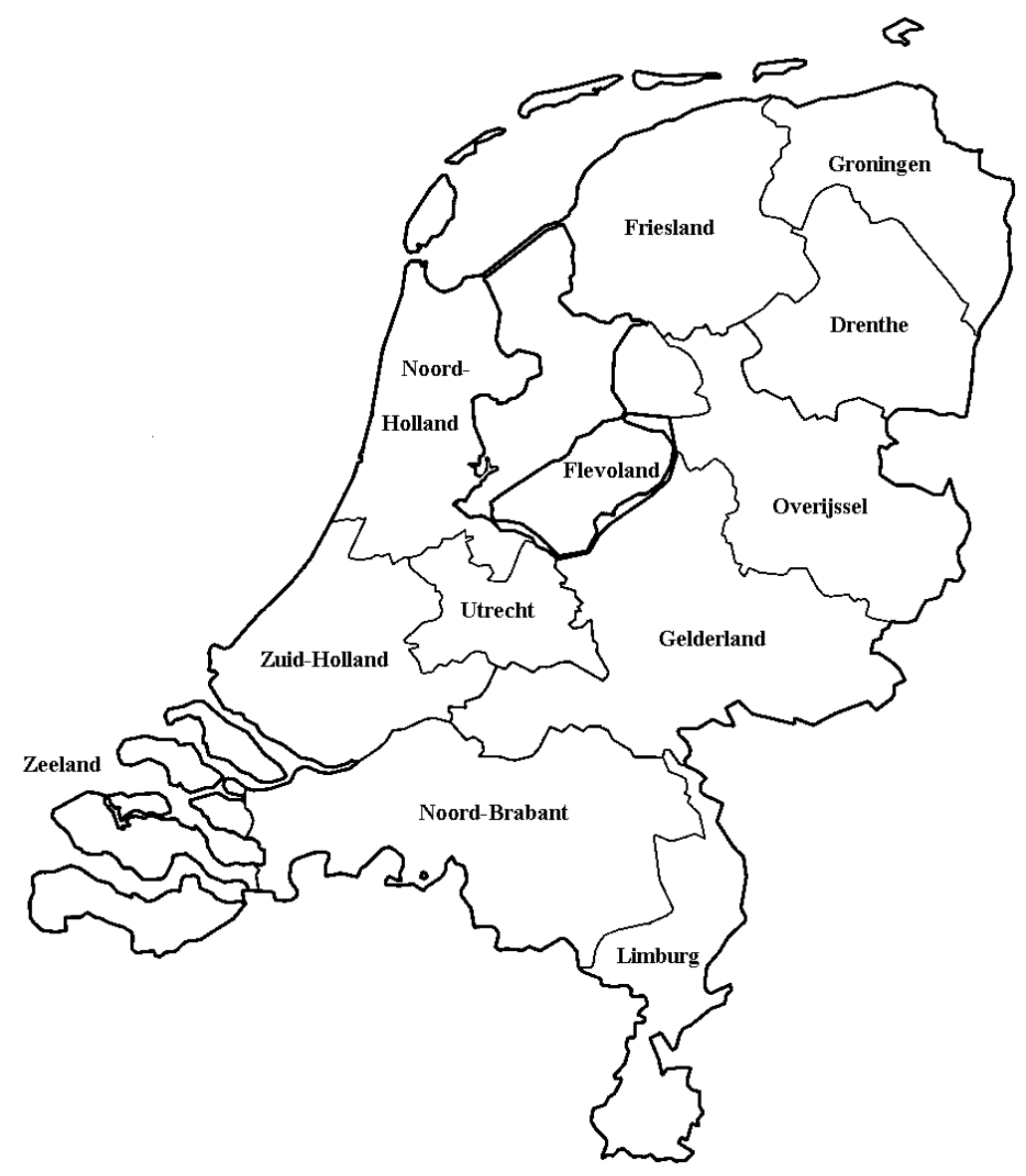

Figure 1

Regional Structure of the Netherlands

Fout! Bladwijzer niet gedefinieerd. 
More details about the data sources are presented in Oude Wansink and Maks (1997). Input-output data is obtained from the input-output tables constructed by Oude Wansink and Maks (1997). We use the input-output tables that are constructed by applying the symmetric adjustment method (Oude Wansink and Maks (1997), section 6).

\section{Regional Convergence in the Netherlands}

The geographical and political organization of the United States and European Union give rise to the analysis of regional economical convergence. In the US, the analysis focusses on the economic development seperate states, whereas the European integration give rise to the evaluation of economic development of the EU members. It can be argued that integration leads to (income) convergence between member states or regions.

Barro and Sala-i-Martin (1995) present the following arguments in support of this view:

"Firms and households of different regions within a single country tend to have access to similar technologies and have roughly similar tastes and cultures. Furthermore, the regions share a common central government and therefore have similar institutional setups and legal systems. [...] Another consideration in the study of regions is that inputs tend to be more mobile across regions than across countries. Legal, cultural, linguistic, and institutional barriers to factor movements tend to be smaller across regions within a country than across countries." (p. 382-383)

Barro and Sala-i-Martin $(1991,1992)$ distinguish between $\beta$ - and $\sigma$-convergence. In the former case, "convergence applies if a poor economy tends to grow faster than a rich one, so that the poor country tends to catch up with the rich one in terms of the level of per capita income or product." (Barro and Sala-i-Martin (1995), p. 383) The latter case "concerns cross-sectional dispersion. In 
this context, convergence occurs if the dispersion -measured, for example, by the standard deviation of the logarithm of per capita income or product across a group of countries or regionsdeclines over time." (Barro and Sala-i-Martin (1995), p. 383)

In Figure 2 (next page), we use these data to picture the annual growth rate and the initial (1980) level of real GDP per worker for 11 Dutch regions. We have no 1980 and 1985 data for Flevoland, so this region is excluded from our analysis. We have also put the growth-level combination for the Netherlands (NL) as a whole in the figure. From Figure 2, a negative relation between the initial level and the growth rate of (real) GDP per worker can be discovered. This negative relation supports the hypothesis of $\beta$-convergence: poor regions grow faster than rich regions. An ordinary linear regression through the points in Figure 2 leads to the following estimated relation between the growth rate and the initial level of GDP

\section{Install Equation Editor and double-} click here to view equation.

where $g_{(Y / L)}$ is the growth rate and $(Y / L)_{0}$ stands for the relative initial level of (real) GDP per worker. ${ }^{2}$ The negative, statistically significant coefficient in the regression equation supports the $\beta$ convergence hypothesis. ${ }^{3}$ For the purpose of comparison, we refer to a result by Baumol (1986), who investigated $\beta$-convergence between main industrial countries during the 1870-1979 period. His result can be described by the following equation

Install Equation Editor and doubleclick here to view equation.

Here, the initial level of GDP per worker is taken relatively to the level of the USA. 


\section{ContainsDatafor}

\section{PostscriptOnly.}

Figure 2

Annual Growth Rate (\%) and

Initial Level of Real GDP per Worker

The Netherlands, 1980-1992, 11 Regions

Before we discuss the differences between Baumol's and our result, we should point at the difference in length between Baumol's and our time period. Nevertheless, some interesting 
conclusions can be made. First, the coefficient in our regression is much more negative than in Baumol's equation, indicating that $\beta$-convergence is stronger between regions (within a country) than between countries. Second, although the constant term and coefficient in our regression are statistically significant (see note 3), the independent variable seems to explain only little of the variation in the dependent variable. The fit of Baumol's equation is much better. Probably, there is conditional convergence between regions in the Netherlands, whereas convergence between industrial countries is unconditional. ${ }^{4}$ Regional differences (in the quality of land, labour, etcetera) are then incorporated in the plans of both regional and national policy makers, whereas international competition forces the national economies to keep up with developments in the world.

With respect to $\sigma$-convergence, we present the coefficient of variation of the 11 Dutch regions in Figure 3 (next page). The coefficient of variation is defined as the standard deviation of the distribution of regional GDP per worker, divided by the average regional GDP per worker.

\section{ContainsDatafor \\ PostscriptOnly.}

Figure 3

Coefficient of Variation

Real GDP per Worker

The Netherlands, 1980-1992, 11 Regions

Fout! Bladwijzer niet gedefinieerd. 
No straightforward conclusion can be drawn from this figure, because the dispersion in regional incomes increased between 1980 and 1985 and decreased between 1985 and 1990. Furthermore, between 1990 and 1992, the dispersion remained constant. Although the coefficients of 1980 and 1992 may support the hypothesis of regional $\sigma$-convergence, we cannot discover a smooth regional $\sigma$-convergence pattern between those years.

The next step in the analysis of regional convergence concerns the explanation of the observed development of regional differences in GDP per worker. Fagerberg and Verspagen (1996), for example, relate the regional growth of labour productivity to several explanatory variables. These variables, among which the number of $R \& D$ employees in the business sector and the number of EU-sponsored R\&D projects, are assumed to describe the ability of regions to catch up. In this paper, we follow another track in explaining regional convergence patterns. First, we introduce a more detailed sectoral analysis, since we think that processes like falling behind, catching up, imitation and innovation take place within sectors of industries. Or, more important, the economic development of sectors within one region may differ, each of which may influence regional performance. Second, we will concetrate on changes in sectoral production structures as a cause for regionally converging incomes.

We think that the regional availability of intermediary goods, qualified labour and physical capital goods is crucial for a sector's choice of the technique to be used in that region. A shortage of a specific input at the regional level may be a reason for, for example, lagging behind other regions.

Before we turn to our own approach, we will discuss the different catching up strategies of 
regions. Regions can choose between 3 different strategies: (a) they improve the efficiency of badly performing sectors, (b) they specialize in the production of better performing sectors or (c) they improve efficiency in all sectors, regardless of the sectors' relative performance. In our approach, we assume that regions choose either the first or the last strategy, and we will first present evidence that regions don't choose the specialization strategy. Regional specialization may lead to $\beta$ convergence when regions increase output in those sectors in which they have a leading position. However, only when income growth in better performing sectors in high-income regions is lower than income growth in better performing sectors in low-income regions, specialization leads to $\beta$ convergence. In order to test for regional specialization, we estimated the following equation

where $x$ is the sector's output share in total regional or national output, subscripts $t_{1}$ and $t_{0}$ refer to periods 1 respectively 0 , and $Y / L$ is real GDP per working hour. Error term $e$ is assumed to be normally distributed with zero mean. The independent variable at the right hand side of equation 1 describes the GDP per worker in a sector of a region relative to the national GDP per worker. If this variable exceeds unity, then the real GDP per worker in that sector is higher than the national one. The dependent variable at the left hand side describes the change in the regional output share of a sector, net from the average national change in the sector's output share. In other words, when in a region real GDP per worker of a sector is higher than nationally, and the region specializes, then we expect the output share of this sector in that region to increase. Regional specialization takes place when regression coefficient $\beta_{l}$ is positive and significantly different from zero. We have estimated the specialization effect for 3 different time periods: 1980-1985, 1980-1990 and 19801992. ${ }^{5}$ In Table 1 (next page), we have put the main regression results: the sign of the regression coefficient $\beta_{l}$ and its 2-tail significance level.

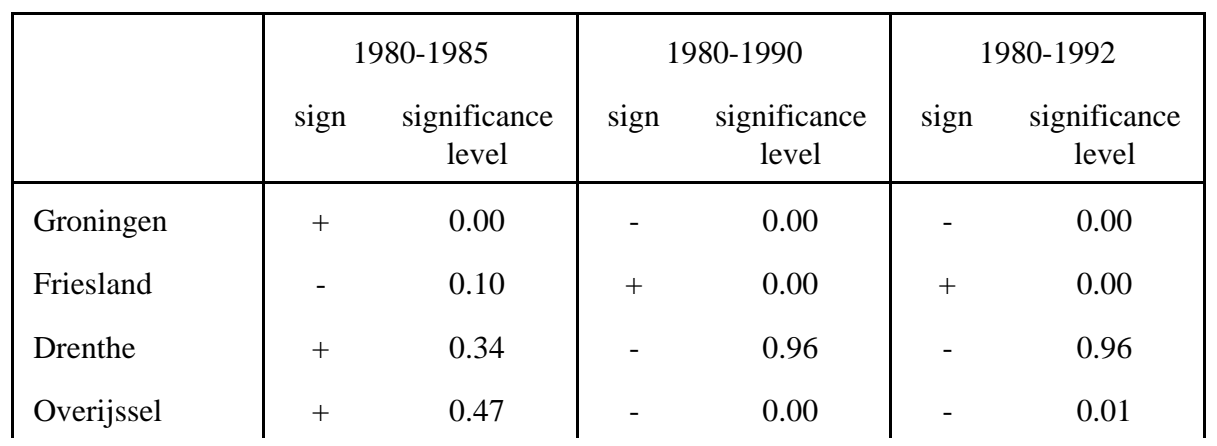




\begin{tabular}{|l|cl|cc|cc|} 
Noord-Holland & + & 0.97 & - & 0.49 & - & 0.35 \\
Zuid-Holland & + & 0.69 & + & 0.68 & + & 0.71 \\
Utrecht & + & 0.15 & - & 0.02 & - & 0.01 \\
Gelderland & + & 0.01 & - & 0.00 & - & 0.00 \\
Noord-Brabant & + & 0.88 & - & 0.00 & - & 0.00 \\
Zeeland & - & 0.59 & - & 0.40 & - & 0.54 \\
Limburg & - & 0.07 & - & 0.00 & - & 0.01 \\
\hline
\end{tabular}

\section{Table 1}

Regression Results on Regional Specialization

(+ 'specialization' - 'despecialization' 2-tail significance level)

The Netherlands, 1980-1985, 1980-1990, 1980-1992, 11 Regions

The results indicate that the hypothesis of sectoral specialization can be rejected for almost all regions. On the contrary, the results rather support the hypothesis that some regions concentrated more on despecialization by stimulating production in those sectors which had a relative bad performance. For Friesland, a pattern of specialization can be found from 1985 onwards (positive sign and a significance level smaller than 0.05), but for Groningen, Overijssel, Utrecht, Gelderland, Noord-Brabant and Limburg a significant process of despecialization can be found in the table (negative sign and a significance level smaller than 0.05). Furthermore, in Drenthe, Noord-Holland, Zuid-Holland and Zeeland, sectoral output expansion is not related to initial sectoral performance at all. By rejecting the hypothesis of regional specialization for almost all regions, another explanation for regional convergence is needed. This is where we start the discussion about our own input-output approach.

\section{The Optimal Input Structure and Technological Distance}

In this section, we will concentrate on the concepts of 'optimal input structure', 'best performing region' and 'technological distance'.

We decompose total inputs of a sector $X$ into intermediary inputs, regional imports, labour inputs, capital inputs and other inputs (which mainly consist of the difference between indirect taxes and indirect subsidies). The specific technology that is used by a sector in a region determines this decomposition of inputs. Therefore, there are differences in relative inputs in the same sectors but in different regions when regional technological differences exist. Based on regional input-output 
tables, we can observe the the typical structure of the sectoral input. So let us define

Install Equation Editor and double-

(2)

click here to view equation.

where $X_{i j}$ is the input, expressed in monetary terms, of input category $j$ in sector $i$ 's input. In our case, these categories are numbered 1 through 34. Numbers 1 through 29 refer to intermediary inputs from other sectors (including the own sector), 30 and 31 refer to interregional and international imports respectively, 32 to the input of capital services, 33 to the input of labour services and 34 to other inputs (mainly the difference between indirect taxes minus indirect subsidies). We will refer to $x_{i j}$ as input or technical coefficients.

Suppose that a specific technique used by a region is superior (in terms of generating income or employment) than techniques used by other regions. This technique, which we will call the 'optimal' technique, can be described by a vector of technical coefficients. We will refer to this vector as the 'optimal input structure' and to the respective region as the 'best performing region'. The set of optimal input structures of all sectors is called the 'optimal input matrix'. Next, by summing the absolute differences between a region's technical coefficients in a sector and the coefficients associated with the optimal input structure, we create an indicator of 'technological distance'. These absolute differences are weighted by their input share. When we define $x^{*}$ as an optimal input coefficient and $n$ as the number of input categories $j$, sector $i$ 's technological distance is given by

\section{Install Equation Editor and double-} click here to view equation.

Superscript $Y / L$ on the left hand side refers to the 'best performing' criterium (here, GDP per worker) that is used for computing the technological distance variable. By definition, the technological distance of the best performing region equals zero. In this paper, we will use the technological distance variable to explain regional economic performance.

The last step is the identification of the optimal input matrix. We must choose an economic criterium by which we measure 'best', or 'optimal'.

\begin{tabular}{|l|cccc|cccc|}
\hline & \multicolumn{4}{|c|}{ GDP per worker } & \multicolumn{3}{|c|}{ Employment per output unit } \\
sector & 1980 & 1985 & 1990 & 1992 & 1980 & 1985 & 1990 & 1992 \\
\hline 1. Agriculture, forestry and fishing & NB & NB & GR & GR & ZE & ZE & NH & NH \\
2. Extraction of minerals and chemical industry & GR & GR & GR & GR & GE & GE & FL & GE \\
3. Food, drink and tobacco industry & NH & DR & NB & NB & ZE & ZE & FL & FL \\
4. Textile industry & NH & UT & NH & NH & DR & GR & GR & GR \\
5. Leather, leather goods, footwear and clothing industry & GR & DR & FL & UT & UT & GR & OV & FL \\
6. Timber and wooden furniture industry & GR & DR & FL & DR & ZE & OV & LI & FL \\
7. Manufacturing of paper and paper products & DR & DR & ZE & ZE & UT & FR & FL & FL
\end{tabular}




\begin{tabular}{|c|c|c|c|c|c|c|c|c|}
\hline 8. Printing and publishing & GR & DR & $\mathrm{NH}$ & NH & DR & FR & $\mathrm{ZE}$ & $\mathrm{ZE}$ \\
\hline 9. Manufacturing of products for construction & GR & NH & $\mathrm{NH}$ & NH & DR & FR & DR & GR \\
\hline 10. Production and preliminary processing of metals & GR & GR & UT & UT & DR & DR & DR & DR \\
\hline 11. Metal products and machinery & GR & DR & NH & $\mathrm{OV}$ & UT & FR & FR & FR \\
\hline 12. Electrical industry & GR & FR & NB & FL & UT & $\mathrm{ZE}$ & FR & $\mathrm{ZE}$ \\
\hline 13. Manufacturing of transport products & DR & $\mathrm{DR}$ & UT & FR & GE & GE & FL & $\mathrm{ZE}$ \\
\hline 14. Other industries & OV & $\mathrm{OV}$ & GR & GR & $\mathrm{ZE}$ & $\mathrm{ZE}$ & $\mathrm{ZE}$ & $\mathrm{ZE}$ \\
\hline 15. Energy and water & $\mathrm{DR}$ & $\mathrm{ZH}$ & FR & GR & NH & $\mathrm{ZE}$ & DR & FL \\
\hline 16. Construction & $\mathrm{ZE}$ & $\mathrm{ZE}$ & $\mathrm{ZH}$ & $\mathrm{ZH}$ & DR & $\mathrm{ZH}$ & DR & DR \\
\hline 17. Wholesale and retail distribution & NB & FR & FL & UT & GR & LI & FR & GR \\
\hline 18. Hotels and catering & FR & $\mathrm{ZE}$ & GR & GR & UT & UT & FR & NH \\
\hline 19. Repair of consumer goods and vehicles & UT & UT & FL & FL & GR & GE & DR & $\mathrm{ZE}$ \\
\hline 20. Transport & $\mathrm{ZE}$ & $\mathrm{ZH}$ & $\mathrm{ZE}$ & NH & UT & UT & UT & UT \\
\hline 21. Communication & $\mathrm{DR}$ & DR & $\mathrm{ZH}$ & FL & UT & $\mathrm{ZE}$ & FL & GR \\
\hline 22. Banking and finance & NH & $\mathrm{NH}$ & NH & $\mathrm{NH}$ & LI & GE & FR & GR \\
\hline 23. Insurance & $\mathrm{ZE}$ & LI & GR & UT & LI & NB & FL & FL \\
\hline 24. Letting of real estate by the owner & LI & $\mathrm{DR}$ & LI & $\mathrm{ZE}$ & $\mathrm{ZH}$ & GR & $\mathrm{ZH}$ & FL \\
\hline 25. Business services and renting & LI & NH & NH & $\mathrm{ZE}$ & $\mathrm{ZH}$ & $\mathrm{ZE}$ & $\mathrm{ZE}$ & DR \\
\hline 26. Medical, health and veterinary services & GR & FR & FL & FL & $\mathrm{LI}$ & $\mathrm{ZE}$ & DR & DR \\
\hline 27. Culture, sport and recreation & $\mathrm{NH}$ & $\mathrm{NH}$ & GR & $\mathrm{ZE}$ & DR & DR & FL & FR \\
\hline 28. Other services & $\mathrm{ZH}$ & $\mathrm{NH}$ & UT & UT & LI & FR & DR & DR \\
\hline 29. Public services & $\mathrm{ZE}$ & $\mathrm{ZE}$ & $\mathrm{ZH}$ & $\mathrm{ZH}$ & UT & GE & GE & GE \\
\hline
\end{tabular}

Table 2

Best Performing Regions

The Netherlands, 1980, 1985, 1990, 1992, 29 Sectors

In this paper, we choose GDP er worker and employment per output unit, since regional policy generally aims at increasing regional income and employment. From our definition it is obvious that the best performing region is not the same in every sector. Furthermore, regional economic performance changes over time, which means that the name of the best performing region changes over time too. In Table 2, we present an overview of the best performing region for 29 sectors in 1980, 1985, 1990 and 1992, based on our two economic criteria. Note that we included Flevoland (FL) in Table 2, since the development of this new region in comparison with the other Dutch regions is quite remarkable and very well described by Table 2. Both the regional performance differences between sectors and the changes of best perfoming region over time can be observed in Table 2.

With respect to GDP per worker, Groningen was best performing region in 9 sectors in 1980, whereas this number decreased to only 5 in 1992. Flevoland, the new region, was in the lead in 4 sectors in 1992. With respect to employment per output unit, Utrecht was best performing region in 8 sectors in 1980, but this number fell to only 1 sector in 1992. Flevoland was best performing region in 7 (!) sectors in 1992. It is striking to note that 'best perfomance' has nothing to do with the 
seize or the economical strength of a region. Zuid-Holland (ZH), economically the largest region in the Netherlands, was best performing region in only 2 sectors in 1992 when it comes to GDP per worker. In case of employment per output unit, Zuid-Holland had no leading position in any of the 29 sectors in 1992. Note, however, that we cannot draw any normative conclusion on these observations, they are only descriptive.

In the next two sections we use the concept of technological distance to measure its impact on economic distances between regions and their economic development.

\section{Technological Distance and Economic Development: GDP per Worker}

In this section, we use technological distance to measure its impact on the economic performance of regions. In this section, economic performance is measured by GDP per worker. In section 3, we used both the level and the growth rate of GDP per worker in order to analyze regional convergence in the Netherlands. Therefore, we relate technological distance to both the level and the growth rate of GDP per worker. The higher the level or the growth rate of GDP per worker, the better performs the sector. For every region, we estimate an equation which relates the relative performance of sectors to their technological distance. In case of the level of GDP per worker, the equation to be estimated is as follows

Install Equation Editor and doubleclick here to view equation.

where superscript ${ }^{\prime} *$ ' refers to the best performing sector (which may actually be the sector in the own region). In equation 4, the level of GDP per worker of sectors, relative to the level of the best performing sectors, is related to the technological distance of these sectors. In other words, if the own region is best performing (highest level of GDP per worker) in a sector then the relative GDP per worker equals 1 and the technological distance equals 0 . A worse performing sector has a lower relative GDP per worker and a higher technological distance. We expect $\beta_{l}$ to be negative.

In case of the growth of GDP per worker, the equation to be estimated is as follows

In equation 5, the growth of GDP per worker of sectors, extracted from the growth of the best performing sectors, is related to the technological distance (in the base year) of these sectors.

In other words, if the own region is best performing (highest growth rate of GDP per worker) in a 
sector then both the relative growth at the left hand side of equation 5 and the technological distance at the right hand side of equation 5 are equal to 0 . In case of a worse performing sector, both variables will be positive so that we expect $\beta_{l}$ to be positive.

In Table 3, we summarize the most relevant regression results. The signs of the regression coefficient $\beta_{l}$ turned out to be as expected in both the GDP level and growth regressions. Therefore, in Table 3, we only present an overview of the significance levels at which the null hypothesis can be rejected that the regression coefficient is equal to zero. In addition, we put the values of the adjusted $\mathrm{R}^{2}$ in the table in order to conclude about the fit of the regression.

\begin{tabular}{|c|c|c|c|c|c|c|c|c|c|c|c|c|c|c|}
\hline & \multicolumn{14}{|c|}{ GDP per Worker } \\
\hline & \multicolumn{8}{|c|}{ level } & \multicolumn{6}{|c|}{ growth } \\
\hline & \multicolumn{2}{|c|}{1980} & \multicolumn{2}{|c|}{1985} & \multicolumn{2}{|c|}{1990} & \multicolumn{2}{|c|}{1992} & \multicolumn{2}{|c|}{ 1980-1985 } & \multicolumn{2}{|c|}{ 1985-1990 } & \multicolumn{2}{|c|}{$1990-1992$} \\
\hline & leve & $\operatorname{adj} R^{2}$ & level & $\operatorname{adj} R^{2}$ & level & $\operatorname{adj} R^{2}$ & level & $\operatorname{adj} R^{2}$ & level & $\operatorname{adj} R^{2}$ & level & $\operatorname{adj} R^{2}$ & level & $\operatorname{adj} R^{2}$ \\
\hline Groningen & $* *$ & 0.39 & $* *$ & 0.42 & $* *$ & 0.31 & $* *$ & 0.56 & $* *$ & 0.33 & $* *$ & 0.22 & $*$ & 0.06 \\
\hline Friesland & ** & 0.48 & ** & 0.45 & ** & 0.28 & ** & 0.55 & * & 0.07 & - & 0.03 & $* *$ & 0.16 \\
\hline Drenthe & ** & 0.55 & ** & 0.57 & ** & 0.17 & ** & 0.26 & ** & 0.14 & ** & 0.31 & * & 0.09 \\
\hline Overijssel & $* *$ & 0.69 & ** & 0.59 & ** & 0.72 & ** & 0.79 & - & 0.01 & $* *$ & 0.25 & $* *$ & 0.16 \\
\hline Noord-Holland & $* *$ & 0.58 & ** & 0.75 & ** & 0.70 & ** & 0.82 & - & 0.00 & ** & 0.26 & $* *$ & 0.16 \\
\hline Zuid-Holland & $* *$ & 0.51 & ** & 0.57 & ** & 0.69 & ** & 0.72 & - & 0.04 & ** & 0.10 & - & 0.00 \\
\hline Utrecht & ** & 0.56 & ** & 0.66 & ** & 0.68 & ** & 0.76 & - & 0.03 & ** & 0.35 & - & 0.05 \\
\hline Gelderland & $* *$ & 0.62 & $* *$ & 0.66 & $* *$ & 0.73 & $* *$ & 0.75 & $* *$ & 0.21 & $*$ & 0.07 & - & 0.00 \\
\hline Noord-Brabant & $* *$ & 0.57 & $* *$ & 0.59 & $* *$ & 0.86 & $* *$ & 0.81 & - & 0.01 & ** & 0.17 & $* *$ & 0.13 \\
\hline Zeeland & $* *$ & 0.30 & ** & 0.47 & $* *$ & 0.49 & ** & 0.64 & - & 0.04 & ** & 0.16 & $* *$ & 0.13 \\
\hline Limburg & $* *$ & 0.62 & ** & 0.57 & $* *$ & 0.67 & $* *$ & 0.72 & - & 0.00 & $*$ & 0.08 & - & 0.06 \\
\hline
\end{tabular}

Table 3

GDP per Worker and Technological Distance

The Netherlands, 1980-1992, 11 Regions

level $=$ significance level of regression coefficient:

- = not significantly different from zero

* = significantly different from zero $(<2$-tail $10 \%)$

$* *$ = significantly different from zero $(<2$-tail $5 \%)$

$\operatorname{adj} R^{2}=$ adjusted $R^{2}$ of the regression equation $(N=29)$

From Table 3 we can see that there exist a strong relationship between the level of GDP per worker and technological distance. This means that low-GDP per worker sectors have an input structure that differs more from the best performing sector than high-GDP per worker sectors.

This supports our view that regional catching-up best takes place by imitating best performing techniques. A comparison between the input structure of the own region's sectors with the input structure of best performing sectors can then reveal structural weaknesses in the own region. This will be discussed at the end of this section.

We can not draw such clear conclusions when we relate the growth of GDP per worker to technological distance. Apart from the statistical insignificancy of some of the regression 
coefficients, the fit of the regressions is very bad. It is obvious that the techniques of equally growing regions aren't necessarily similar in the base year and therefore, technological distance cannot explain growth of GDP per worker. However, regional convergence doesn't necessarily have to be explained by such a relation. In the case of regional convergence, the region with the initially lowest income has the highest growth rate. In our regression analysis it is then assumed that the best performing technique is the one applied in the region with the highest growth rate. In conclusion, the best performing technique (in terms of growth) can be found in the initially poorest region. The poorest region, however, uses an old technique, because 'imitating' or 'catching-up' describes a process in which an old technique is exchanged for $a$ new technique in order to approach the newest technique (which is best performing in terms of the income level). Therefore, the poorer regions have different technologies and therefore different input structures. A clear relation between income growth and technological distance can therefore not be established.

In the context of these results, it's worthwhile to take short notice of the dynamics behind the process of catching up. A region can decide to update older technologies, but while adjusting, another best performing technique comes already about. This is not always caused by improving the technique itself, but also by changing conditions in, for instance, factor markets. These changes may make another technique more profitable than the current best performing technique. Remember that we measure economic performance by means of the (growth of) GDP per worker, and that techniques are evaluated by means of their income-generating capacity.

Before we turn to the application of our second economic criterium in the next section, we come back to the analysis of regional structural weaknesses and the policy implications of our findings. Because of the strong relation between the level of GDP per worker and technological distance, we are able to point at the structural weaknesses in regions.

By comparing the sectoral input structures in the own region with the optimal input structures, it can be discovered whether there is regionally a surplus or a shortage output from one of the input categories. The recommended change in output can be derived by the following equation 


\begin{tabular}{|c|c|c|c|c|c|c|c|c|c|c|c|}
\hline 1. Agriculture, forestry and fishing & 1.7 & -4.2 & -7.5 & -1.9 & 12.3 & -0.3 & 11.0 & -3.6 & -2.1 & -7.1 & -5.0 \\
\hline 2. Extraction of minerals and chemical industry & -1.3 & 5.0 & -1.6 & 1.3 & 3.1 & -10.6 & 15.2 & 20.7 & -0.0 & -12.1 & -6.0 \\
\hline 3. Food, drink and tobacco industry & 0.8 & -1.0 & 0.0 & 0.4 & 0.5 & 2.8 & -3.3 & -2.4 & -2.8 & 0.4 & 2.2 \\
\hline 4. Textile industry & 42.5 & -2.2 & 2.3 & -4.2 & -1.8 & 16.2 & -2.8 & -4.4 & -5.1 & 2.5 & -4.0 \\
\hline 5. Leather, leather goods, footwear and clothing industry & 11.5 & 8.3 & -3.3 & -4.4 & -5.5 & 7.8 & -0.0 & -3.5 & -6.3 & -6.3 & -5.3 \\
\hline 6. Timber and wooden furniture industry & 1.6 & -4.0 & 9.7 & -4.3 & 5.4 & -1.7 & -4.1 & -4.9 & -6.0 & -0.0 & -3.9 \\
\hline 7. Manufacturing of paper and paper products & -2.0 & $\overline{4.7}$ & 0.9 & 19.3 & -0.8 & 29.6 & 2.4 & -4.4 & -1.8 & -12.4 & -5.6 \\
\hline 8. Printing and publishing & 2.8 & 12.5 & 7.8 & 0.9 & -11.9 & -2.8 & -8.9 & 7.8 & 3.6 & 19.3 & 6.5 \\
\hline 9. Manufacturing of products for construction & -5.4 & -3.8 & 11.3 & 8.9 & 46.3 & -2.9 & -3.5 & -4.5 & -3.8 & 10.1 & -10.3 \\
\hline 10. Production and preliminary processing of metals & -9.5 & 22.7 & 457.1 & -5.1 & -13.0 & -6.0 & 18.4 & -8.3 & -12.2 & -17.2 & -9.6 \\
\hline 11. Metal products and machinery & 6.9 & -0.9 & -3.7 & -2.5 & -3.2 & -1.6 & -3.9 & -0.7 & -3.7 & -9.4 & -5.9 \\
\hline 12. Electrical industry & 0.4 & -0.3 & -4.7 & -3.3 & -6.0 & -3.7 & -5.7 & -0.6 & -6.5 & -4.2 & -5.3 \\
\hline 13. Manufacturing of transport products & 2.8 & -0.7 & -2.8 & 0.2 & -1.0 & -0.5 & 18.6 & 8.3 & -1.8 & -2.5 & -2.1 \\
\hline 14. Other industries & -2.6 & 5.4 & -4.9 & 2.8 & 0.2 & -2.3 & -2.6 & 1.4 & -1.9 & -4.5 & -4.1 \\
\hline 15. Energy and water & -2.2 & 0.6 & 11.0 & 2.7 & -6.9 & -4.0 & -6.3 & 2.8 & 2.9 & -14.2 & -3.0 \\
\hline 16. Construction & 7.1 & 3.3 & 2.9 & 4.1 & -0.3 & -0.8 & -1.3 & 6.1 & 2.7 & -0.8 & 4.4 \\
\hline 17. Wholesale and retail distribution & 2.4 & 1.4 & 0.8 & 1.1 & -0.4 & -0.5 & -0.7 & 0.9 & 0.2 & -0.5 & 0.8 \\
\hline 18. Hotels and catering & 5.8 & 1.0 & 0.2 & 2.2 & -2.7 & -0.1 & -0.7 & 2.1 & 1.4 & -5.2 & -1.6 \\
\hline 19. Repair of consumer goods and vehicles & 2.0 & 0.2 & -0.8 & 4.2 & -1.1 & -0.8 & -0.8 & 3.0 & 1.1 & -2.6 & 3.7 \\
\hline 20. Transport & 3.6 & 6.0 & 6.8 & 6.4 & -1.5 & -1.4 & 3.7 & 6.5 & 5.2 & -0.2 & 3.5 \\
\hline 21. Communication & -4.8 & -0.1 & 12.6 & 2.9 & -4.9 & -7.0 & -7.7 & 8.1 & 3.9 & 4.8 & 5.5 \\
\hline 22. Banking and finance & 3.9 & 0.3 & 4.1 & 3.6 & -1.9 & 1.4 & -1.1 & 2.9 & 0.8 & -1.0 & 3.5 \\
\hline 23. Insurance & 22.3 & 1.0 & 7.6 & 22.1 & -0.1 & -2.7 & -3.4 & 4.5 & 9.9 & 18.2 & -0.1 \\
\hline 24. Letting of real estate by the owner & 1.7 & 0.3 & -0.7 & 1.9 & -0.7 & -0.8 & -1.2 & 0.9 & 0.3 & -2.0 & -0.2 \\
\hline 25. Business services and renting & 11.7 & 13.7 & 13.1 & 16.9 & -12.9 & -12.8 & -13.4 & 7.5 & 3.6 & 16.6 & 12.6 \\
\hline 26. Medical, health and veterinary services & -0.6 & 0.5 & -0.2 & 0.2 & -0.6 & -0.3 & -0.9 & -0.0 & -0.0 & -0.3 & -0.7 \\
\hline 27. Culture, sport and recreation & 3.7 & -0.3 & -0.1 & 4.4 & -5.4 & -0.4 & -1.1 & 2.0 & 1.6 & -0.0 & 0.5 \\
\hline 28. Other services & 1.3 & 1.9 & 1.2 & 4.1 & -0.9 & -1.4 & -2.4 & 1.3 & 3.2 & -0.8 & 1.9 \\
\hline 29. Public services & 0.5 & 0.6 & -0.2 & 1.1 & -0.9 & -1.6 & -1.4 & -0.3 & 0.6 & -2.2 & 0.1 \\
\hline 30. Interregional imports & -11.9 & -12.5 & -14.7 & -27.7 & 7.3 & 5.3 & 7.7 & -30.0 & -10.1 & 3.5 & -12.5 \\
\hline 31. International imports & 1.7 & -2.4 & -5.1 & -10.5 & -8.4 & -22.5 & -6.9 & -7.6 & -6.5 & -30.7 & -13.3 \\
\hline 32. Capital services & 2.5 & 2.0 & 14.0 & 20.5 & 15.2 & 44.7 & 16.3 & 19.8 & 19.3 & 68.8 & 32.0 \\
\hline 33. Labour services & -7.9 & -5.8 & -10.5 & -7.6 & -3.9 & -5.8 & -7.3 & -5.8 & -6.5 & -9.3 & -10.6 \\
\hline
\end{tabular}

\section{Table 4}

Recommended Output Increases (>0) and Decreases $(<0)$

(\% of current output)

The Netherlands, 1992, 11 Regions

In Table 4 (previous page), we present these recommended increases and decreases in regional inputs for all Dutch regions and all sectors for 1992. The increases and decreases are expressed in percentages of 1992 output. With respect to some inputs, hardly any change is needed in any region. Examples are wholesale and retail distribution (17), medical, health and veterinary services (26) and public services (29). Other inputs need more restructuring, such as production and preliminary processing of metals (10), interregional imports (30) and capital services (32). Especially the last one is very interesting, because it turns out that the input share of capital services 
need to be increased in all regions. In contradiction, the input share of labour services need to be decreased in all regions. As a conclusions, our results show that, on average, best performing technologies are capital intensive and labour extensive.

Another phenomenon can be discovered in Table 4. In general, an exchange of economic activities needs to take place between on the one hand the "West" (Noord-Holland, Zuid-Holland and Utrecht) and on the other the rest of the Netherlands. A clear example can be found in the input categories printing and publishing (8) and business services and renting (25), of which their output should decrease in the "West" and increase in the rest of the Netherlands.

At the end of this section, we can conclude that technological distance explains regional income differences quite well. On the other hand, regional differences in income growth cannot be explained by technological distance. The dynamic aspects of the process of regional convergence make it impossible to establish a relationship between a region's growth rate and its relative technological position. Comparing own input structures with optimal input structures makes it possible to reveal the economic weaknesses of the own region. In the next section, we use technological distance to explain regional differences in employment per output unit.

\section{Technological Distance and Economic Development: Employment per Output Unit}

In this section, we do the same as in the previous section, but with another economic criterium: employment per output unit. The reason for selecting this particular criterium is the fact that the variable has two policy-faces. On the one hand, economic growth is stimulated by encouraging the investment in newly developed, mostly labour saving technologies. This development decreases employment per output unit. On the other hand, high unemployment rates must be avoided by creating an extra amount of jobs at a cost as low as possible.

This development increases employment per output unit. Because we already looked, though in an indirect way, at the former development in the previous section, we concentrate on the latter development in this section. The criterium for good economic performance is then formulated as: the higher the (growth of) employment per output unit, the better the regional performance. By selecting the best performing regions for all sectors, we analyze again the relation between (the growth of) employment per output unit and technological distance. The idea here is that regional policy makers are in search of labour intensive technologies in order to decrease regional unemployment. 
We investigated the relation between (the growth of) employment per output unit and technological distance in a way which is analogous to the analysis in the previous section. In case of the relation between the level of employment per output unit and technological distance, we estimated the following equation

For the same reasons as mentioned in the previous section (equation 4), we expect $\beta_{l}$ to be negative. In case of the relation between the growth of employment per output unit and technological distance, we estimated the following equation

Install Equation Editor and double-

click here to view equation.

For the same reasons as mentioned in the previous section (equation 5), we expect $\beta_{1}$ to be positive.

In Table 5 (next page), we summarize the most relevant regression results. The signs of the regression coefficient $\beta_{l}$ turned out to be as expected in both the employment level and growth regressions. Therefore, in Table 5, we only present an overview of the significance levels at which the null hypothesis can be rejected that the regression coefficient is equal to zero. From Table 5 we can see that there exists a strong relationship between the level of employment per output unit and technological distance. This means that low-employment per output unit sectors have an input structure that differs more from the best performing sector than high-employment per output unit sectors. In this case, catching up in terms of employment goals best takes place by imitating best performing techniques. Again, as in the previous section, a comparison between the input structure of the own region's sectors with the input structure of best performing sectors can reveal structural weaknesses in the own region. This will be discussed at the end of this section. 


\begin{tabular}{|c|c|c|c|c|c|c|c|c|c|c|c|c|c|c|}
\hline & \multicolumn{14}{|c|}{ Employment per Output Unit } \\
\hline & \multicolumn{8}{|c|}{ level } & \multicolumn{6}{|c|}{ growth } \\
\hline & \multicolumn{2}{|c|}{1980} & \multicolumn{2}{|c|}{1985} & \multicolumn{2}{|c|}{1990} & \multicolumn{2}{|c|}{1992} & \multicolumn{2}{|c|}{$1980-1985$} & \multicolumn{2}{|c|}{$1985-1990$} & \multicolumn{2}{|c|}{$1990-1992$} \\
\hline & level & $\operatorname{adj} R^{2}$ & level & $\operatorname{adj} R^{2}$ & level & $\operatorname{adj} R^{2}$ & level & $\operatorname{adj} R^{2}$ & level & $\operatorname{adj} R^{2}$ & level & $\operatorname{adj} R^{2}$ & level & $\operatorname{adj} R^{2}$ \\
\hline Groningen & $* *$ & 0.40 & $* *$ & 0.44 & $* *$ & 0.38 & $* *$ & 0.41 & $* *$ & 0.19 & $* *$ & 0.13 & $* *$ & 0.14 \\
\hline Friesland & $* *$ & 0.53 & $* *$ & 0.58 & $* *$ & 0.41 & $* *$ & 0.36 & * & 0.08 & $* *$ & 0.68 & - & 0.00 \\
\hline Drenthe & $* *$ & 0.41 & $* *$ & 0.36 & $* *$ & 0.35 & $* *$ & 0.38 & - & 0.03 & $* *$ & 0.35 & - & 0.00 \\
\hline Overijssel & $* *$ & 0.23 & $* *$ & 0.75 & $* *$ & 0.51 & $* *$ & 0.29 & $* *$ & 0.13 & $* *$ & 0.66 & - & 0.04 \\
\hline Noord-Holland & $* *$ & 0.37 & $* *$ & 0.29 & $* *$ & 0.35 & $* *$ & 0.54 & $*$ & 0.08 & $* *$ & 0.19 & - & 0.02 \\
\hline Zuid-Holland & $* *$ & 0.44 & $* *$ & 0.61 & $* *$ & 0.36 & $* *$ & 0.22 & $* *$ & 0.35 & $* *$ & 0.38 & - & 0.01 \\
\hline Utrecht & $* *$ & 0.54 & ** & 0.55 & $* *$ & 0.61 & $* *$ & 0.57 & - & 0.06 & $* *$ & 0.46 & - & 0.04 \\
\hline Gelderland & $* *$ & 0.31 & $* *$ & 0.65 & $* *$ & 0.39 & $* *$ & 0.30 & - & 0.05 & $* *$ & 0.54 & - & 0.02 \\
\hline Noord-Brabant & $* *$ & 0.26 & $* *$ & 0.42 & $* *$ & 0.38 & $* *$ & 0.22 & $* *$ & 0.21 & $* *$ & 0.40 & - & 0.05 \\
\hline Zeeland & $* *$ & 0.43 & $* *$ & 0.84 & $* *$ & 0.53 & $* *$ & 0.28 & $*$ & 0.06 & $* *$ & 0.35 & $* *$ & 0.23 \\
\hline Limburg & $* *$ & 0.20 & $* *$ & 0.26 & $* *$ & 0.37 & $* *$ & 0.13 & $* *$ & 0.32 & $* *$ & 0.38 & - & 0.02 \\
\hline
\end{tabular}

Table 5

Employment per Output Unit and Technological Distance

The Netherlands, 1980-1992, 11 Regions

level $=$ significance level of regression coefficient:

- = not significantly different from zero $(>2$-tail $10 \%)$

$*$ = significantly different from zero $(<2$-tail $10 \%)$

$* *$ = significantly different from zero $(<2$-tail $5 \%)$

$\operatorname{adj} R^{2}=$ adjusted $R^{2}$ of the regression equation $(N=29)$

We find a striking pattern over time when we look at the relationship between the growth of employment per output unit and technological distance. In the 1980-1985 period, the results are mixed, but in the 1985-1990 period, a strong relation between those variables can be established in all regions. In the 1990-1992 period, a significant relationship can only be found for 2 regions. As shown in Figure 4 (next page), both the 1980-1985 and the 1990-1992 periods are characterized by an increasing (broad) unemployment rate, whereas (broad) unemployment dropped significantly in the 1985-1990 period. This decrease in (broad) unemployment was accompanied by an increase in the employment rate. In the 1980-1985 period, the employment rate decreased, and in the 19901992 period it remained constant. In conclusion, during the recovery in the labour market in the 1985-1990 period, regions with high growth in employment per output unit used similar techniques (measured by input structures). Considering the labour market developments in the $80 \mathrm{~s}$, it is however not surprising to observe changes of best performing region in 20 out of 29 sectors between 1980 and 1985, and in 22 sectors between 1985 and 1990 (see Table 2).

Before we conclude this section, we come back to the weaknesses analysis, like we did in the previous section. Again, we will describe the necessary changes in sectoral output in order to create the highest employment per output unit as possible. 


\section{ContainsDatafor}

\section{PostscriptOnly.}

Figure 4

Unemployment Rate and Employment Rate

The Netherlands, 1970-1994

Source: OECD (1996), p. 41.

In Table 6 (next page), we present these recommended increases and decreases in regional inputs for all Dutch regions and all sectors for 1992. The increases and decreases are expressed in 
percentages of 1992 output. With respect to some inputs, hardly any change is needed in any region. Examples are medical, health and veterinary services (26) and public services (29). Other inputs need more restructuring, such as the textile industry (4), manufacturing of paper and paper products (7) and the production and preliminary processing of metals (10). Furthermore, as we would expect, Table 6 shows that technologies generating a higher level of employment per output unit are labour intensive: all regions need to increase labour services (33). With respect to capital services, the results differ between the regions. Capital services should relatively decrease in the regions in the north (Groningen, Friesland, Drenthe and Overijssel) and increase in the other regions. In the former case, capital should be substituted by labour, whereas in the latter case, capital services seem to be complementary to labour services in order to achieve a higher level of employment per output unit.

The general pattern discovered in the previous section, where the recommended development for the "West" (Noord-Holland, Zuid-Holland and Utrecht) is of the opposite direction than for the other regions, is not present in Table 6. 


\begin{tabular}{|c|c|c|c|c|c|c|c|c|c|c|c|}
\hline Sector & GR & FR & DR & OV & NH & $\mathrm{ZH}$ & UT & GE & NB & $\mathrm{ZE}$ & $\mathrm{LI}$ \\
\hline 1. Agriculture, forestry and fishing & 3.7 & -2.0 & -7.9 & -0.7 & 17.0 & 1.1 & 17.9 & -1.1 & 0.1 & -7.3 & -5.2 \\
\hline 2. Extraction of minerals and chemical industry & -2.0 & 0.6 & -2.3 & 0.3 & -0.8 & -11.3 & 10.8 & 12.2 & -1.0 & -12.9 & -7.4 \\
\hline 3. Food, drink and tobacco industry & -2.6 & -5.6 & -5.3 & -4.3 & -3.5 & -1.3 & -7.1 & -7.0 & -7.4 & -4.1 & -3.1 \\
\hline 4. Textile industry & 58.3 & -5.7 & -1.6 & -7.4 & -6.9 & 9.7 & -8.1 & -8.0 & -8.9 & 1.5 & -7.5 \\
\hline 5. Leather, leather goods, footwear and clothing industry & 19.2 & 4.3 & -3.9 & -6.3 & -8.0 & 6.4 & -4.2 & -6.1 & -7.7 & -4.5 & -6.9 \\
\hline 6. Timber and wooden furniture industry & 1.4 & -8.2 & 3.3 & -7.5 & -2.1 & -5.8 & -10.1 & -8.0 & -9.6 & -1.4 & -7.8 \\
\hline 7. Manufacturing of paper and paper products & -5.2 & -4.6 & 1.7 & 27.9 & 7.6 & 65.7 & 10.2 & -12.3 & -5.7 & -9.9 & -9.8 \\
\hline 8. Printing and publishing & 0.4 & 7.1 & 2.7 & -5.0 & -17.5 & -6.7 & -13.8 & 2.3 & -2.4 & 19.0 & 1.3 \\
\hline 9. Manufacturing of products for construction & -7.6 & -11.3 & 0.8 & -1.1 & 26.9 & -10.8 & -13.5 & -9.9 & -11.3 & 2.4 & -11.6 \\
\hline 10. Production and preliminary processing of metals & -12.4 & 1.7 & 367.4 & -15.4 & -18.5 & -14.1 & -5.0 & -16.4 & -17.4 & -21.1 & -18.3 \\
\hline 11. Metal products and machinery & 17.5 & 1.6 & 0.1 & -0.4 & -0.8 & 3.6 & -1.8 & 1.1 & -1.6 & -3.4 & -3.9 \\
\hline 12. Electrical industry & 4.0 & 1.0 & -2.8 & -1.7 & -4.6 & -1.5 & -4.3 & 0.4 & -5.0 & -1.1 & -3.8 \\
\hline 13. Manufacturing of transport products & 2.3 & -0.5 & -2.5 & 0.4 & -2.1 & -1.5 & 16.3 & 7.3 & -1.5 & -2.5 & -1.9 \\
\hline 14. Other industries & 3.0 & 13.0 & -3.2 & 8.8 & 8.7 & 5.3 & 5.0 & 7.0 & 2.3 & 3.5 & 0.2 \\
\hline 15. Energy and water & 6.1 & 3.2 & 16.5 & 7.3 & -2.9 & 2.6 & -2.3 & 4.8 & 7.1 & -6.8 & 1.2 \\
\hline 16. Construction & 5.2 & -0.0 & -0.3 & 0.9 & -3.8 & -3.7 & -4.7 & 2.6 & -0.7 & -2.9 & 1.2 \\
\hline 17. Wholesale and retail distribution & 3.4 & 0.7 & 0.4 & 0.3 & -1.3 & -1.0 & -1.7 & 0.2 & -0.6 & 0.1 & 0.2 \\
\hline 18. Hotels and catering & 9.0 & 1.1 & 1.1 & 2.3 & -3.6 & -0.0 & -1.8 & 1.7 & 1.1 & -3.2 & -1.1 \\
\hline 19. Repair of consumer goods and vehicles & 3.6 & 1.0 & -0.2 & 4.6 & -0.7 & 0.0 & 0.3 & 3.5 & 1.4 & -1.2 & 4.5 \\
\hline 20. Transport & 1.7 & 2.2 & 3.7 & 2.7 & -4.9 & -4.5 & -0.5 & 2.2 & 1.7 & -2.5 & 0.1 \\
\hline 21. Communication & -1.9 & 2.6 & 14.7 & 4.8 & 1.0 & -4.3 & -4.6 & 9.9 & 6.2 & 12.4 & 8.3 \\
\hline 22. Banking and finance & 2.8 & -0.4 & 2.7 & 1.7 & -3.0 & -0.3 & -2.6 & 1.2 & -0.8 & -1.7 & 2.1 \\
\hline 23. Insurance & 9.2 & -11.5 & -5.4 & 6.6 & -13.7 & -15.6 & -16.5 & -9.0 & -4.9 & 6.5 & -12.6 \\
\hline 24. Letting of real estate by the owner & 2.8 & 0.3 & -0.5 & 1.9 & -0.8 & -0.6 & -1.5 & 0.8 & 0.2 & -0.9 & -0.2 \\
\hline 25. Business services and renting & 23.2 & 9.2 & 11.3 & 10.7 & -16.9 & -13.4 & -17.7 & 2.3 & -3.0 & 31.8 & 8.5 \\
\hline 26. Medical, health and veterinary services & -0.4 & 0.6 & -0.1 & 0.4 & -0.3 & -0.1 & -0.6 & 0.1 & 0.1 & -0.2 & -0.5 \\
\hline 27. Culture, sport and recreation & 3.7 & -0.7 & -0.5 & 3.7 & -6.0 & -0.7 & -1.5 & 1.4 & 1.0 & -0.1 & 0.2 \\
\hline 28. Other services & 2.6 & 1.5 & 1.0 & 3.7 & -1.5 & -1.3 & -3.0 & 0.8 & 2.5 & 0.8 & 1.7 \\
\hline 29. Public services & 3.8 & 1.6 & 1.0 & 2.1 & -0.1 & -0.1 & -0.8 & 0.2 & 1.4 & 1.2 & 1.4 \\
\hline 30. Interregional imports & 18.1 & 1.8 & -0.8 & -16.1 & 27.8 & 32.1 & 32.7 & -17.7 & 2.4 & 32.4 & 1.4 \\
\hline 31. International imports & 38.2 & 4.5 & 9.2 & -2.8 & -5.9 & -7.5 & -4.5 & -5.1 & -1.8 & -7.4 & -5.3 \\
\hline 32. Capital services & -41.2 & -13.6 & -13.1 & -1.6 & 0.8 & 5.5 & 4.2 & 6.7 & 1.7 & 1.3 & 3.5 \\
\hline 33. Labour services & 29.5 & 11.6 & 10.6 & 8.0 & 13.6 & 17.9 & 3.4 & 8.4 & 9.5 & 26.8 & 9.4 \\
\hline
\end{tabular}

\section{Table 6}

Recommended Output Increases $(>0)$ and Decreases $(<0)$

(\% of current output)

The Netherlands, 1992, 11 Regions

We can however reach at another interesting conclusion from Table 6. The larger regions (Noord-

Holland and Zuid-Holland), which account for approximately $40 \%$ of the national product of the Netherlands, need to increase their interregional imports and decrease their international imports in order to increase their level of employment per output unit. From this result we can conclude that international imports form a threat for employment perspectives in the Netherlands. Of course the question remains to be answered whether Dutch producers will be able to compete with foreign 
producers, which is beyond the scope of this paper.

This concludes our analysis of the relation between (the growth of) employment per output unit and technological distance of regions. There is a strong relation between the level of employment per output unit and technological distance. Although the results are mixed in case of the growth of employment per output unit, a striking time pattern can be discovered which can be associated with developments in the labour market. Finally, we can sum deviations from optimal input structures over input categories in order to find weaknesses in the regional production structure. The larger regions need to substitute international imports by interregional imports in order to increase the level of employment per output unit.

\section{Summary and Conclusions}

The starting point of this paper was the analysis of regional convergence in the Netherlands between 1980 and 1992. In section 3, we showed that $\beta$-convergence occurred between the Dutch regions. Our results also indicated that convergence is conditional. Policy makers aiming at converging economic performance have 3 policy options. They can improve the efficiency of badly performing sectors, they can stimulate specialization by encouraging output increases in better performing sectors or they can improve efficiency in all sectors, regardless of their relative performance. To find support for our input-output approach, we first showed that regional specialization didn't take place in the Netherlands between 1980 and 1992.

A sector's technology can be described by the sector's input structure. Given the sector's economic performance in each region, measured by GDP per worker or employment per output unit, we call the input structure of the best performing region the 'optimal input structure'. The best performing region is not the same in every sector and change over time within sectors. The sum of (absolute) deviations from the optimal input structure in another region is called its 'technological distance'. In this paper we investigated the relation between a region's economic performance and its technological distance.

In section 5, we showed that a strong negative relation exists between the level of GDP per worker and technological distance. This supports our view that regional catching-up best takes place by imitating best performing techniques. A clear relation between the growth rate of GDP per worker and technological distance cannot be established. 
Furthermore, we investigated the deviations from the optimal input structure in all sectors and regions, based on the relation between GDP per worker and technological distance, and found that an exchange of economic activities needs to take place between the "West" (Noord-Holland, ZuidHolland and Utrecht) and the rest of the Netherlands. In addition, the input of capital needs to be increased, whereas labour input should decrease. In order to reach a higher level of GDP per worker, regions should therefore invest in capital intensive, labour saving technologies.

In section 6, we repeated our analysis of the relation between economic performance and technological distance, but this time economic performance was measured by employment per output unit. The reason for selecting this particular criterium is the fact that the variable has two policy-faces. On the one hand, economic growth is stimulated by encouraging the investment in labour saving technologies, as we concluded in section 5. This would decrease employment per output unit. On the other hand, high unemployment rates must be avoided by creating an extra amount of jobs at a cost as low as possible. Such a development would increase employment per output unit. It turned out that there exists a strong negative relation between the level of employment per output unit and technological distance. Therefore, catching up in terms of employment goals best takes place by imitating best performing techniques. Although no strong evidence was found for a relation between the growth of employment per output unit and technological distance, a striking time pattern of this relation was discovered which can be linked to labour market developments. When the labour market recovers, a relation seems to be existent. By analyzing the deviations from the optimal input structure for all sectors and regions, based on the relation between the level of employment per output unit and technological distance, our results showed that especially larger regions (Noord-Holland and Zuid-Holland) need to substitute international imports by interregional imports. From this result we can conclude that international imports form a threat for employment goals in the Netherlands.

We presented an analysis of the relation between the economic performance of regions and their technological distance based on two policy goals: increasing GDP per worker and increasing employment per output unit. In both cases, we came up with recommendations with respect to changes in regional inputs. We therefore end this paper by comparing these recommended changes in order to find out whether they are consistent with eachother or not. 
For instance in Table 4, the recommended change in the agricultural input (1) in Groningen (GR), based on achieving the highest GDP per worker as possible, is an increase $(+1.7 \%)$. In Table 6 , the recommended change in the agricultural input (1) in Groningen (GR), based on achieving the highest employment per output unit as possible, is also an increase $(+3.7 \%)$. In conclusion, the recommended policies in this case are not contradicting, that is they both prescribe an increase in output. In Table 7, we have summarized the number of conflicting policies for all input categories.

\begin{tabular}{|c|c|c|}
\hline Input category & $\begin{array}{c}\text { Number of Regions with } \\
\text { Conflicting Policies }\end{array}$ & $\%$ \\
\hline 1. Agriculture, forestry and fishing & 2 & $18 \%$ \\
\hline 2. Extraction of minerals and chemical industry & 1 & $9 \%$ \\
\hline 3. Food, drink and tobacco industry & 7 & $64 \%$ \\
\hline 4. Textile industry & 1 & $9 \%$ \\
\hline 5. Leather, leather goods, footwear and clothing industry & 0 & $0 \%$ \\
\hline 6. Timber and wooden furniture industry & 1 & $9 \%$ \\
\hline 7. Manufacturing of paper and paper products & 2 & $18 \%$ \\
\hline 8. Printing and publishing & 2 & $18 \%$ \\
\hline 9. Manufacturing of products for construction & 1 & $9 \%$ \\
\hline 10. Production and preliminary processing of metals & 1 & $9 \%$ \\
\hline 11. Metal products and machinery & 4 & $36 \%$ \\
\hline 12. Electrical industry & 2 & $18 \%$ \\
\hline 13. Manufacturing of transport products & 0 & $0 \%$ \\
\hline 14. Other industries & 6 & $55 \%$ \\
\hline 15. Energy and water & 3 & $27 \%$ \\
\hline 16. Construction & 3 & $27 \%$ \\
\hline 17. Wholesale and retail distribution & 2 & $18 \%$ \\
\hline 18. Hotels and catering & 0 & $0 \%$ \\
\hline 19. Repair of consumer goods and vehicles & 2 & $18 \%$ \\
\hline 20. Transport & 1 & $9 \%$ \\
\hline 21. Communication & 2 & $18 \%$ \\
\hline 22. Banking and finance & 3 & $27 \%$ \\
\hline 23. Insurance & 4 & $36 \%$ \\
\hline 24. Letting of real estate by the owner & 0 & $0 \%$ \\
\hline 25. Business services and renting & 1 & $9 \%$ \\
\hline 26. Medical, health and veterinary services & 2 & $18 \%$ \\
\hline 27. Culture, sport and recreation & 0 & $0 \%$ \\
\hline 28. Other services & 1 & $9 \%$ \\
\hline 29. Public services & 3 & $27 \%$ \\
\hline 30. Interregional imports & 4 & $36 \%$ \\
\hline 31. International imports & 2 & $18 \%$ \\
\hline 32. Capital inputs & 4 & $36 \%$ \\
\hline 33. Labour inputs & 11 & $100 \%$ \\
\hline
\end{tabular}

Table 7

Conflicting Policies in Regions

The Netherlands, 1992, 33 Input Categories 
Simultaneously increasing GDP per worker and employment per output unit leads to the highest number of conflicting policies in regions in the inputs from the food, drink and tobacco industry (category $3,64 \%$ of the regions), other industries $(14,55 \%)$ and labour services $(33,100 \%)$. No conflicting policies can be found in the inputs from the leather, leather goods, footwear and clothing industry (5), manufacturing of transport products (13), hotels and catering (18), letting of real estate by the owner (24) and culture, sport and recreation (27). In general, the number of conflicting policies is quite low.

In Table 8, we present the number of conflicting policies in input categories for all regions. Again, we can conclude that the number of conflicting policies is generally very low: Overijssel, Utrecht and Limburg have conflicting policies in $15 \%$ of the input categories. The highest values can be found in Friesland (33\%) and Noord-Brabant (33\%).

\begin{tabular}{|l|c|c|}
\hline Region & $\begin{array}{c}\text { Number of Input Categories } \\
\text { with Conflicting Policies }\end{array}$ & $\%$ \\
\hline Groningen & 6 & $18 \%$ \\
\hline Friesland & 11 & $33 \%$ \\
\hline Drenthe & 9 & $27 \%$ \\
\hline Overijssel & 5 & $15 \%$ \\
\hline Noord-Holland & 6 & $18 \%$ \\
\hline Zuid-Holland & 8 & $24 \%$ \\
\hline Utrecht & 5 & $15 \%$ \\
\hline Gelderland & 6 & $18 \%$ \\
\hline Noord-Brabant & 11 & $33 \%$ \\
\hline Zeeland & 6 & $18 \%$ \\
\hline Limburg & 5 & $15 \%$ \\
\hline
\end{tabular}

Table 8

Conflicting Policies in Input Categories

The Netherlands, 1992, 11 Regions

This concludes our analysis of the economic performance of regions and their technological distance to the Dutch technology frontier. Our analysis will be more complete when more regions from other countries are included in the framework, but the results are promising for regional policy makers aiming at increasing regional income, employment and welfare. 


\section{Notes}

$\mathrm{n}$ this paper, we may sometimes use the following abbreviations for the Dutch regions (from the north to the sor =Groningen, FR=Friesland, DR=Drenthe, OV=Overijssel, FL=Flevoland, NH=Noord-Holland, ZH=Zuid-Holli $=$ Utrecht, GE=Gelderland, NB=Noord-Brabant, ZE=Zeeland and LI=Limburg. Somtimes we will refer to the Netherlands le by using the NL abbreviation.

he initial (1980) level of real GDP per worker of a region is taken relatively to the initial (1980) level of real GDP per wo re Netherlands.

he standard errors of the constant term and the regression coefficient are 1.92 and 1.94, respectively. The absolute $t$-values constant term and the regression coefficient both exceed 2.35 , which means that both estimated values significantly differ $\mathrm{f}$ , (evaluated at the 5\% 2-tail significance level).

$\mathrm{n}$ the case of conditional convergence, regions move to different steady states. These differences can be explained by o ors, such as the quality of the labour force. In the case of unconditional convergence, regions move to the same steady st for example Broadberry (1996)).

Ne also estimated equation 1 for the 1985-1990 and 1985-1992 periods in order to test for differences in the base $\mathrm{y}$ vever, the results of these estimates were similar to the 1980-1990 and 1980-1992 periods, respectively. 


\section{References}

Barro, R.J. and X. Sala-i-Martin (1991), "Convergence across States and Regions", Brookings Papers on Economic Activity, no. 1, 107-182.

Barro, R.J. and X. Sala-i-Martin (1992), "Convergence", Journal of Political Economy, 100, 2 (April), 223-251.

Barro, R.J. and X. Sala-i-Martin (1995), Economic Growth, McGraw-Hill, Inc., New York.

Baumol, W.J. (1986), "Productivity Growth, Convergence, and Welfare: What the Long-Run Data Show", American Economic Review, 76, 5 (December), 1072-1085.

Fagerberg, J. and B. Verspagen (1996), "Heading for Divergence? Regional Growth in Europe Reconsidered", Journal of Common Market Studies, 34, 3 (September), 431-448.

OECD (1996), "Netherlands", Economic Surveys 1995-1996.

Oude Wansink, M.J. and J.A.H. Maks (1997), "On the Construction of Regional IO Tables", paper prepared for the congress of the European Regional Science Association, Rome, Italy, August 1997, University of Maastricht. 
Annex 1 Classification of Sectors

\begin{tabular}{|l|l|}
\hline Sector Description & NACE Rev.1 \\
\hline Code \\
\hline 2. Agriculture, forestry and fishing & $01-05$ \\
2. Extraction of minerals and chemical industry & $10-14,23-26$ \\
3. Food, drink and tobacco industry & $15-16$ \\
4. Textile industry & $17-18$ \\
5. Leather, leather goods, footwear and clothing industry & 19 \\
6. Timber and wooden furniture industry & 20,36 \\
7. Manufacturing of paper and paper products & 21 \\
8. Printing and publishing & 22 \\
9. Manufacturing of products for construction & 20 \\
10. Production and preliminary processing of metals & 27 \\
11. Metal products and machinery & $28-29$ \\
12. Electrical industry & $30-33$ \\
13. Manufacturing of transport products & $34-35$ \\
14. Other industries & $36-37$ \\
15. Energy and water & $40-41$ \\
16. Construction & 45 \\
17. Wholesale and retail distribution & 51 \\
18. Hotels and catering & 55 \\
19. Repair of consumer goods and vehicles & 50,52 \\
20. Transport & $60-63$ \\
21. Communication & 64 \\
22. Banking and finance & 65,67 \\
23. Insurance & 66 \\
24. Letting of real estate by the owner & 70 \\
25. Business services and renting & $71-74$ \\
26. Medical, health and veterinary services & 85 \\
27. Culture, sport and recreation & $90-93$ \\
28. Other services & 95 \\
29. Public services & 75,80 \\
\hline
\end{tabular}

Fout! Bladwịzer niet gedefinieerd. 